\title{
PERBANDINGAN UNJUK KERJA RESIN PENUKAR ION BASA KUAT DOWEX MARATHON A DENGAN PUROLITE PADA PROSES PEMURNIAN BIOGAS SKALA PILOT PLANT
}

\author{
Dyah Retno Sawitri ${ }^{1}$, M. Haekal Arkan ${ }^{2}$, Endhika Yasa Pradikta ${ }^{3}$, \\ M. Khoirul Ummam ${ }^{4}$, Anies Mutiari ${ }^{5}$
}

\author{
Jurusan Teknik Kimia, Fakultas Teknologi Industri, Universitas Islam Indonesia ${ }^{1,2,3,4)}$, \\ Jl. Kaliurang Km 14,5, Sleman, Yogyakarta, 55584 \\ Balai Besar Bahan dan Barang Teknik Kementrian Perindustrian Republik Indonesia ${ }^{5)}$ \\ Jl. Sangkuriang No. 14 Bandung Indonesia \\ E-mail:dyah.retno@uii.ac.id
}

\begin{abstract}
Adsorption of carbon dioxide is a vital process in biogas purification. A previous study has narrowed down the choice of ion exchange resins for the adsorption process into two commercial resins, Dowex Marathon A, and Purolite. Dowex Marathon A boasts the advantage of having no need of any pretreatments to use. Purolite, although needing pretreatment before usage, costs only roughly a third of Dowex Marathon A. The objective of the study is to decide on which resin is best suited to commercially produce biogas free from pollutants, most of which is carbon dioxide. Both resins at their fresh state were tested for durability by checking on levels of carbon dioxide content at set time intervals. Results suggest the Purolite resin to be more durable than the Dowex Marathon A resin. Data of gas passing through Dowex showed relatively high concentration of $\mathrm{CO}_{2}$ after 10 minutes of operation. While Purolite showed its first signs of $\mathrm{CO}_{2}$ after 20 minutes of operation. Further tests are conducted to compare fresh and regenerated Pirolite resins. Comparison between fresh and postregeneration Purolite showed relatively consistent results where the regenerated resin showed its first signs of $\mathrm{CO}_{2}$ after 25 minutes.
\end{abstract}

Keywords : $\mathrm{CO}_{2}$ Removal, Adsorption, Strong Base Ion Exchange Resin; Biogas Purification.

\section{PENDAHULUAN}

Kebutuhan energi nasional yang semakin meningkat dan isu lingkungan telah menjadi pendorong lahirnya penelitian yang berbasis pada produksi sumber daya energi terbarukan dengan memanfaatkan bahan baku bernilai ekonomi rendah. Salah satu sumber daya energi terbarukan yang sedang banyak dikaji adalah biogas. Biogas, dengan kandungan utama gas metana $\left(\mathrm{CH}_{4}\right)$ adalah gas yang dihasilkan melalui proses fermentasi bahan - bahan organik secara anaerob. Bahan - bahan organik untuk produksi biogas dapat berupa kotoran manusia dan hewan, limbah organik dari rumah tangga, dan limbah organik lain yang bersifat biodegradable. Gas yang dihasilkan umumnya adalah campuran gas yang terdiri dari gas metan $\left(\mathrm{CH}_{4}\right)$ sekitar 55-70\%, karbondioksida $\left(\mathrm{CO}_{2}\right)$ sejumlah 25-50\%, nitrogen $\left(\mathrm{N}_{2}\right)$ sekitar $0-5 \%$, uap air $1,5 \%$,
$\mathrm{H}_{2} \mathrm{~S}$ sebesar $0-0,5 \%$ dan sedikit amoniak sebesar $0-0,05 \% \quad\left(\mathrm{NH}_{3}\right)$ (Mutiari, 2014). Dengan komposisi tersebut, nilai kalor biogas sekitar 22000-25000 kJ.m ${ }^{-3}$.

Proses pemurnian biogas perlu dilakukan untuk meningkatkan konsentrasi gas $\mathrm{CH}_{4}$ sekaligus mengurangi konsentrasi gas lain yang berpotensi menurunkan kualitas biogas seperti gas $\mathrm{CO}_{2}$ dan gas $\mathrm{H}_{2} \mathrm{~S}$. Gas $\mathrm{CO}_{2}$ akan mengurangi nilai kalor pembakaran. Pengurangan gas $\mathrm{CO}_{2}$ dalam biogas akan secara signifikan meningkatkan kualitas biogas dan sekaligus meningkatkan nilai kalor hingga $39000 \mathrm{~kJ} \cdot \mathrm{m}^{-3}$ (Yin et al, 2010). Sedangkan keberadaan gas $\mathrm{H}_{2} \mathrm{~S}$ di dalam produk pada konsentrasi tertentu dapat bersifat racun, merusak katalis dan menyebabkan korosi. Fokus penelitian ini adalah pada proses pemurnian biogas dengan mengurangi konsentrasi gas $\mathrm{CO}_{2}$. 
Beberapa metode yang dapat digunakan untuk mengurangi konsentrasi gas $\mathrm{CO}_{2}$ dalam biogas antara lain adalah dengan absorbsi menggunakan air (Nock et al, 2010), absorbsi kimia (Liu et al, 2014), adsorpsi dengan padatan (Santos et al, 2013) dan pemisahan dengan membran (Basu et al, 2010). Setiap metode yang diusulkan memiliki kelebihan dan kekurangan baik dalam hal biaya, kompleksitas dan efektivitas proses pemurnian. Pemurnian biogas untuk mengambil gas $\mathrm{CO}_{2}$ menggunakan resin merupakan gabungan antara proses absorbsi dengan proses adsorpsi dan belum banyak dilakukan. Padatan resin yang telah dibasahi dengan air memiliki kapasitas sebagai media pertukaran ion, dimana gas $\mathrm{CO}_{2}$ yang telah terserap dalam air (melalui proses absorbsi) membentuk ion karbonat yang selanjutnya dipertukarkan dengan ion yang terikat dalam resin (melalui proses adsorpsi). Jenis resin yang digunakan dalam penelitian ini adalah resin penukar basa kuat (strong base ion exchange resin).

Pada penelitian sebelumnya telah dipilih dua resin komersial yaitu Dowex Marathon $A$ dan Purolite. Kedua resin komersial tersebut merupakan resin penukar basa kuat tipe I. Resin tipe I merupakan jenis resin yang mempunyai bentuk fisik seperti telur ikan, dan mempunyai pori - pori di dalamnya sehingga luas permukaan totalnya sangat besar. Resin jenis tersebut cocok digunakan pada proses adsorpsi karena luas permukaannya yang besar sehingga dapat menjerap ion karbonat yang dihasilkan dari karbondioksida lebih banyak.

Penelitian pada skala laboratorium menggunakan resin komersial telah dilakukan untuk membandingkan unjuk kerja masing-masing resin, unjuk kerja resin sebelum dan sesudah diregenerasi, serta perbandingan unjuk kerja alat dengan satu dan tiga kolom. Hasil penelitian tersebut kemudian digunakan untuk merancang peralatan pemurnian biogas pada skala pilot plant. Lokasi dimana peralatan tersebut dibangun terletak di Kecamatan Srandakan Kabupaten Bantul, Yogyakarta. Lokasi tersebut dipilih berdasarkan pertimbangan bahwa di tempat tersebut terdapat kelompok ternak dan telah berproduksi tiga reaktor biogas atau digester dengan kapasitas masing-masing $24 \mathrm{~m}^{3}$. Biogas yang dihasilkan dari ketiga digester tersebut selama ini dimanfaatkan sebagai bahan bakar proses memasak beberapa warung / rumah makan di sekitar Pantai Baru. Selain itu, biogas juga telah dimanfaatkan sebagai sumber energi genset yang dinyalakan untuk keperluan rapat di kandang kelompok ternak tersebut. Dengan pemasangan peralatan pemurnian biogas di lokasi tersebut, diharapkan mampu meningkatkan efektivitas pemanfaatan dari biogas yang telah digunakan selama ini dan mencegah terjadinya korosi pada kompor maupun genset yang digunakan.

Penelitian ini dilakukan untuk menguji alat pemurnian biogas skala pilot yang telah dirancang dan dibangun sebelumnya. Unjuk kerja dari kedua jenis resin komersial tersebut dievaluasi untuk kemudian dibandingkan hasilnya. Unjuk kerja resin sebelum dan sesudah diregenerasi juga akan dievaluasi. Hasil dari penelitian ini diharapkan dapat memberikan informasi mengenai jenis resin yang memberikan unjuk kerja lebih baik sehingga menghasilkan biogas dengan kemurnian tinggi dan biaya operasional yang minimum.

\section{METODOLOGI PENELITIAN}

\subsection{Bahan dan Alat}

Bahan yang digunakan dalam penelitian ini meliputi aquadest, $\mathrm{NaOH}$ teknis, resin Dowex Marathon A, resin Purolite, dan biogas yang dihasilkan dari Kelompok Ternak Pandan Mulyo Srandakan, Kabupaten Bantul. Sedangkan alat yang digunakan adalah instalasi pemurnian biogas skala pilot plant tiga kolom yang terletak di Kelompok Ternak Pandan Mulyo Ngentak, Kecamatan Srandakan, Kabupaten Bantul, Yogyakarta. Instalasi tersebut dirancang dan dibangun oleh tim khusus dari Balai Besar Bahan dan Barang Teknik (B4T), Kementrian Perindustrian Republik Indonesia. Alat pemurnian tersebut 
terintegrasi dengan digester biogas dengan kapasitas $24 \mathrm{~m}^{3}$. Instalasi pemurnian biogas dapat dilihat pada gambar 1 .

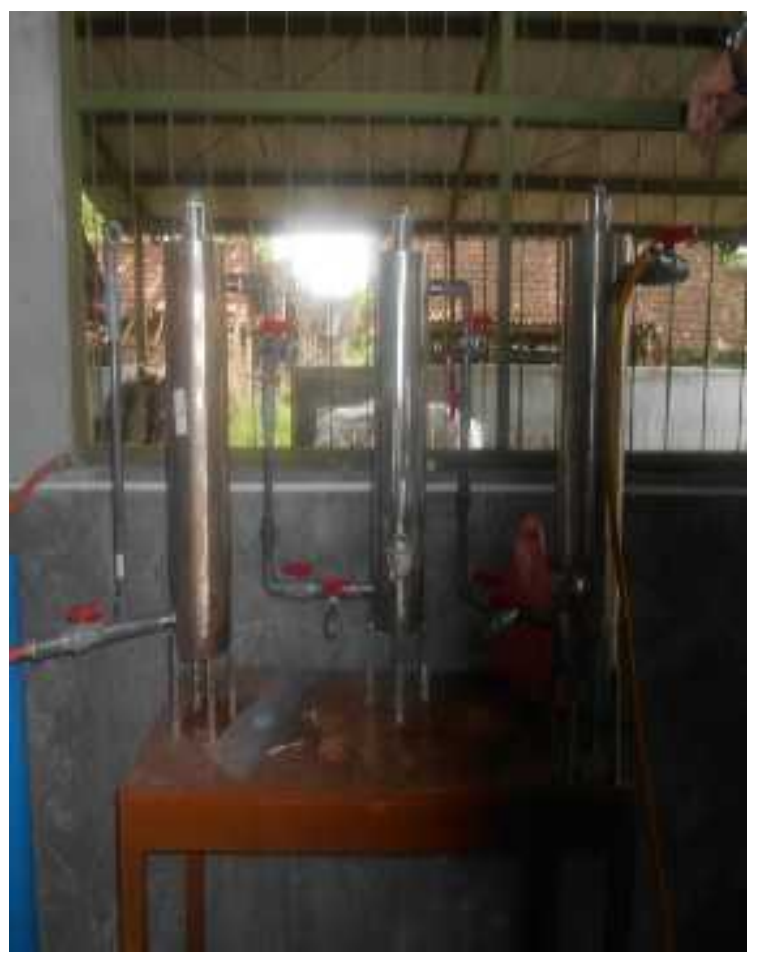

Gambar 1. Instalasi Pemurnian Biogas Skala Pilot Plant.

\subsection{Prosedur Penelitian}

Sebelum digunakan, resin penukar basa kuat dengan merk Dowex Marathon A dicuci menggunakan larutan $\mathrm{NaOH}$. Proses pencucian resin sebelum digunakan pertama kali dimaksudkan supaya butiran resin mengembang (swelling). Resin tersebut kemudian dibasahi menggunakan aquadest dengan perbandingan tertentu sebelum dimasukkan ke dalam kolom adsopsi. Prosedur yang sama juga dilakukan untuk resin penukar basa kuat merk Purolite. Unjuk kerja resin dievaluasi dengan mengambil sampel biogas sebelum masuk kolom adsopsi dan sampel biogas setelah keluar dari kolom adsorpsi setiap periode waktu tertentu.

Sampel gas diambil menggunakan syringe gastight. Konsentrasi gas $\mathrm{CO}_{2}$ dalam sampel dianalisis menggunakan Gas Chromatography. Proses regenerasi dilakukan setelah mengetahui unjuk kerja kedua jenis resin komersial yang digunakan, dimana hanya satu jenis resin saja yang akan dievaluasi unjuk kerjanya sebelum dan setelah diregenerasi. Proses regenerasi dilakukan dengan mengeluarkan resin yang telah jenuh dari kolom adsorpsi. Resin tersebut dicuci menggunakan aquadest dan diaktifkan kembali dengan larutan $\mathrm{NaOH}$. Prosedur selanjutnya sama dengan prosedur awal sebelum regenerasi dilakukan.

\section{HASIL DAN PEMBAHASAN}

Penelitian ini adalah penelitian lapangan yang merupakan lanjutan dari penelitian sebelumnya yang dilakukan di laboratorium. Penelitian yang dilakukan di laboratorium menggunakan biogas hipotetis yang berupa mixed gas (gas $\mathrm{CH}_{4}$ dengan kandungan $60 \%$ $\mathrm{CO}_{2}$ ) dan bertujuan untuk mencari kondisi operasi yang optimum. Sementara penelitian di lapangan menggunakan crude biogas yang dihasilkan langsung dari digester serta bertujuan untuk mengukur unjuk kerja sistem pada skala pilot plant.

Hasil penelitian skala laboratorium dapat dilihat pada gambar 2, yang menunjukkan bahwa unjuk kerja resin komersial Dowex Marathon A lebih baik daripada jenis resin komersial Purolite. Resin Dowex akan memberikan persentase penjerapan $\mathrm{CO}_{2}$ 100\% sampai pada menit ke-7.

Resin Purolite tidak memberikan persentase penjerapan $\mathrm{CO}_{2}$ dari menit pertama saat dilakukan pengambilan sampel. Hal ini disebabkan karena pada penelitian skala laboratorium, perlakuan untuk resin komersial yang baru pertama kali digunakan berbeda. Pada resin komersial jenis Dowex Marathon $A$, kemampuan untuk menjerap gas $\mathrm{CO}_{2}$ relatif baik walaupun tanpa perlakuan awal. Sementara untuk resin komersial Purolite tidak berlaku hal tersebut.

Perlakuan awal (pretreatment) terhadap resin purolite perlu dilakukan untuk memberikan unjuk kerja yang sama dengan resin Dowex. Harga dari resin Purolite adalah sepertiga dari harga resin Dowex. Perlakuan awal terhadap jenis resin komersial Purolite dapat dilakukan dengan cara merendam di dalam larutan $\mathrm{NaOH} 2 \%$. Dengan adanya perlakuan awal terhadap resin Purolite, unjuk kerja yang dihasilkan 
sama dengan jenis resin komersial. Dowex, sehingga dari sisi ekonomi dapat mengurangi modal kerja sistem pemurnian biogas menggunakan bahan isian resin tersebut.

\subsection{Perbandingan Unjuk Kerja Resin Penukar Basa Kuat Dowex Marathon A dengan Purolite}

Pada penelitian skala pilot plant, perlakuan awal untuk kedua jenis resin dibuat sama baik untuk Dowex Marathon A maupun Purolite. Biogas yang digunakan dalam penelitian adalah crude biogas yang dialirkan langsung dari digester. Pengukuran awal menunjukkan bahwa konsentrasi gas $\mathrm{CO} 2$ dalam crude biogas rata - rata adalah $35 \%$. Hasil penelitian dapat dilihat pada gambar 2.

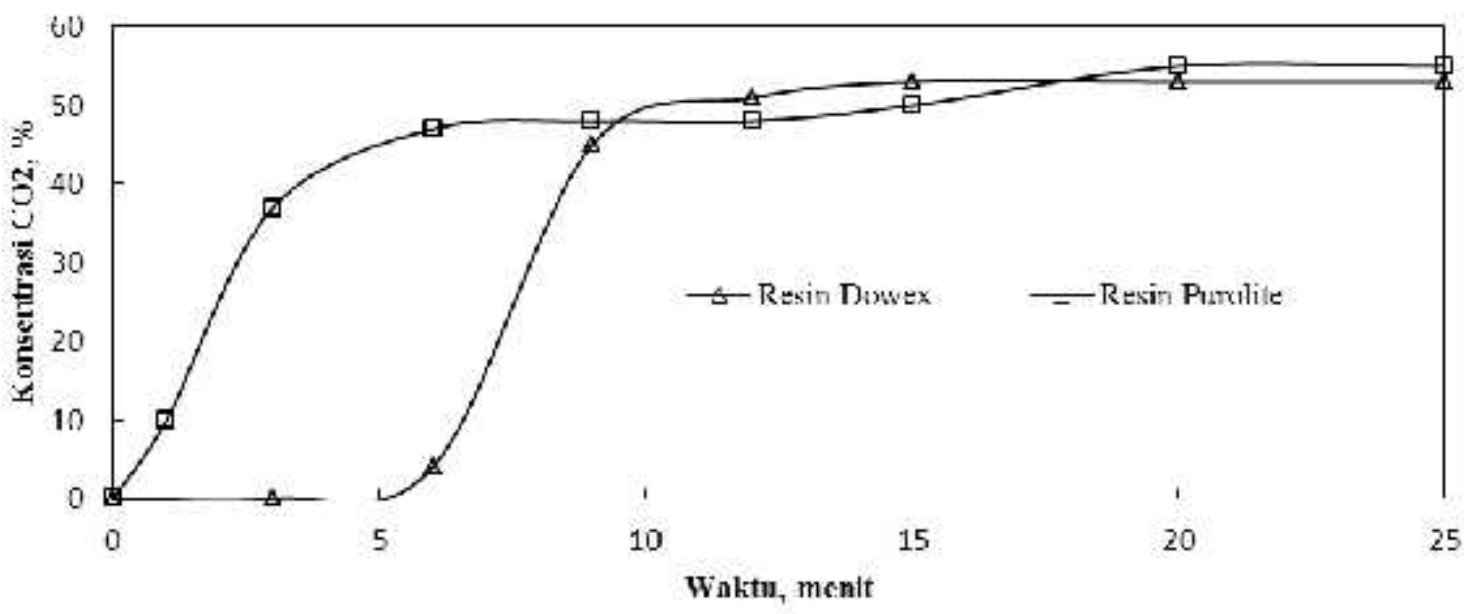

Gambar 2. Perbandingan Unjuk Kerja Resin Dowex Marathon A dengan Purolite dalam Penelitian Skala Laboratorium.

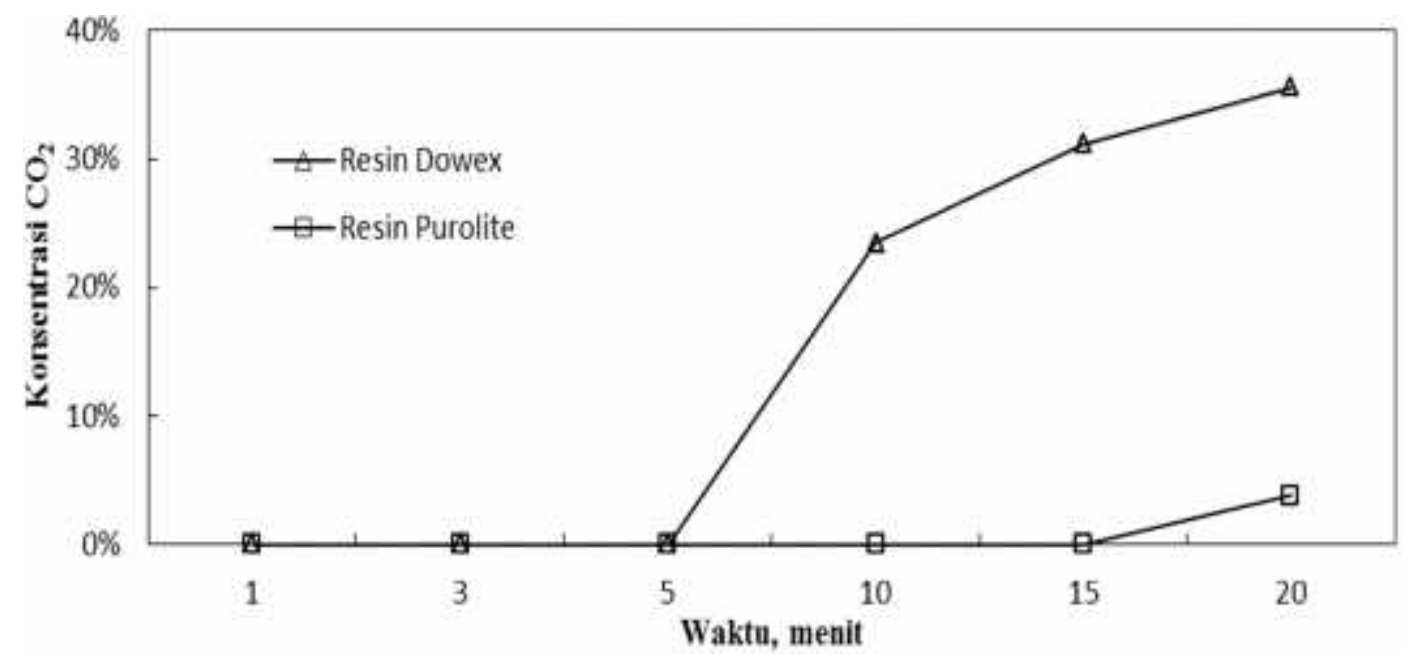

Gambar 3. Perbandingan Unjuk Kerja Resin Dowex Marathon A dengan Purolite dalam Penelitian Skala Pilot Plant.

Dari Gambar 3 dapat dilihat bahwa performa resin Purolite ternyata jauh lebih baik dibandingkan dengan performa resin Dowex Marathon A. Resin Dowex Marathon $A$ memberikan persentase penjerapan $\mathrm{CO}_{2}$ $100 \%$ sampai pada menit ke-5 dan gas $\mathrm{CO}_{2}$ mulai terdeteksi pada menit ke-10. Hal ini sejalan dengan hasil penelitian sebelumnya. Hasil yang berbeda ditunjukkan oleh unjuk kerja resin Purolite dimana resin ini mampu memberikan prosentase penyerapan $\mathrm{CO}_{2}$ $100 \%$ sampai dengan menit ke-15 dengan gas $\mathrm{CO}_{2}$ mulai terdeteksi pada menit ke-20, bertolak belakang dengan hasil penelitian 
sebelumnya. Faktor komposisi gas dan perlakuan awal di yakini merupakan faktor kunci yang menyebabkan perbedaan hasil yang cukup nyata antara penelitian skala laboratorium dan penelitian skala pilot plant. Komposisi gas yang digunakan dalam penelitian skala laboratorium memiliki konsentrasi gas $\mathrm{CO}_{2}$ yang lebih tinggi jika dibandingkan dengan konsentrasi $\mathrm{CO}_{2}$ pada crude biogas, hampir mencapai dua kali lipat. sehingga pada penelitian skala pilot plant, waktu yang diperlukan untuk mendapatkan prosentase kejenuhan 100\% menjadi lebih lama. Perlakuan awal yang diberikan terhadap resin Purolite memberikan performa resin yang lebih baik jika dibandingkan dengan penelitian skala laboratorium yang tanpa perlakuan awal. Untuk resin Dowex Marathon A, hasil yang diperoleh sama yang berarti bahwa perlakuan awal yang diberikan ternyata tidak mempengaruhi performa resin.

Jika dilihat dari segi ekonomi, maka hasil yang diperoleh dari penelitian skala pilot plant menunjukkan kecenderungan yang positif. Mengingat harga resin Purolite yang jauh lebih murah dibandingkan harga resin Dowex Marathon A, maka untuk aplikasi selanjutnya, resin Purolite lebih sesuai untuk digunakan pada pemurnian biogas.

\subsection{Perbandingan Unjuk Kerja Resin Penukar Basa Kuat Purolite Sebelum dan Setelah Diregenerasi}

Hasil penelitian perbandingan unjuk kerja resin menunjukkan bahwa performa resin Purolite lebih baik dibandingkan dengan resin Dowex Marathon A. Dengan hasil tersebut, uji lanjutan untuk membandingkan performa resin sebelum dan setelah diregenerasi hanya dilakukan untuk resin Purolite. Hasil perbandingan dapat dilihat pada gambar 4. Proses regenerasi dilakukan setelah resin digunakan dan telah mencapai kondisi jenuhnya. Dari gambar 4 dapat dilihat bahwa unjuk kerja resin setelah diregenerasi hampir sama dan bahkan lebih baik dibandingkan dengan resin segar. Prosentase penyerapan $100 \%$ dicapai dalam waktu yang lebih lama hingga mencapai 15 menit dan gas $\mathrm{CO}_{2}$ mulai terdeteksi pada menit ke-25. Proses regenerasi yang dilakukan dalam penelitian ini memang hanya dilakukan sebanyak satu kali, namun hasil yang diperoleh menunjukkan kemampuan resin untuk menjerap gas $\mathrm{CO}_{2}$ dari gas campuran masih sangat baik.

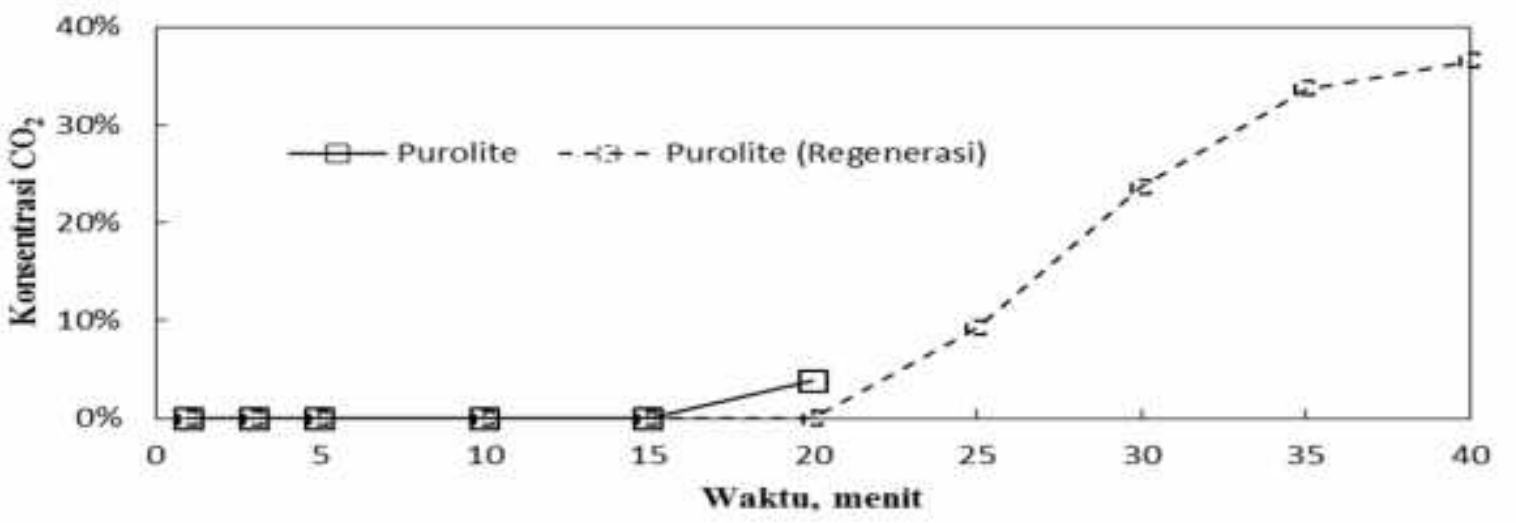

Gambar 4. Perbandingan Unjuk Kerja Resin Purolite Sebelum dan Setelah Di regenerasi dalam Penelitian Skala Pilot Plant.

\section{KESIMPULAN}

Dari hasil penelitian ini dapat diambil kesimpulan bahwa pada aplikasi pemurnian biogas skala pilot plant untuk mengurangi konsentrasi gas $\mathrm{CO} 2$, jenis resin Purolite menunjukkan performa yang lebih baik jika dibandingkan dengan resin Dowex Marathon A. Setelah resin Purolite mengalami kejenuhan $100 \%$, proses regenerasi yang dilakukan menunjukkan hasil yang cukup 
baik. Jika dilihat dari faktor ekonomi dimana harga resin Purolite lebih murah, maka jenis resin tersebut lebih sesuai digunakan untuk aplikasi di lapangan.

\section{DAFTAR PUSTAKA}

Basu, S., Khan, A.L., Cano-Odena, A., Liu, C., Vankelecom, I.F., Membrane - based technologies for biogas separations, Chem. Soc. Rev. 39 750-768, 2010.

Liu, Y.S., Li, H., Wei, G.F., Zhang, H., Li, X.K., Jia, Y.X., Mass transfer performance of $\mathrm{CO} 2$ absorption by alkanolamine aqueous solution for biogas purification, Sep. Purif. Technol. 133 476483, 2014.

Mutiari, A., Desain Peralatan Pemurnian Biogas Dari Kandungan Karbondioksida Skala Pilot Plant, project report, Center of Material and Technical Product, Ministry of Industry, Bandung, Indonesia, 2014.

Nock, W.J., Walker, M., Kapoor, R., Heaven, S., Modeling the water scrubbing process and energy requirements for $\mathrm{CO} 2$ capture to upgrade biogas to biomethane, Ind. Eng. Chem. Res. $5312783-$ 12792, 2014.

Santos, M.P.S., Grande, C.A., Rodrigues, A.E., Dynamic study of the pressure swing adsorption process for biogas upgrading and its responses to feed disturbances, Ind. Eng. Chem. Res. 52 5445-5454, 2013.

Yin, B., Chen, L.M., Kong, Q.P., Research on purification technology for vehicle biogas, Modern Chem. Ind. 29 (11) 28-31, 2009. 